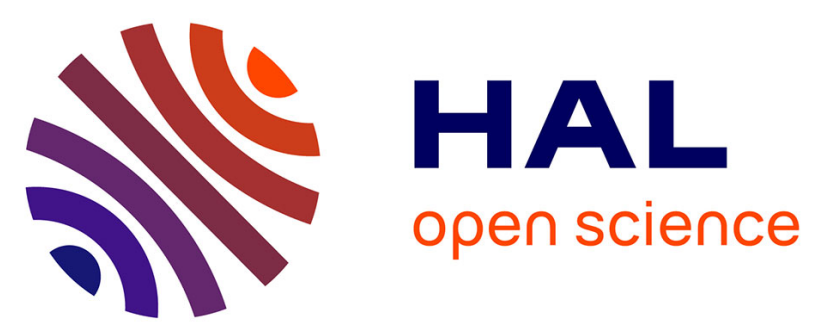

\title{
FLOW CYTOMETRIC DIFFERENTIATION OF AVIAN LEUKOCYTES AND ANALYSIS OF THEIR INTRACELLULAR CYTOKINE EXPRESSION
}

Sandra de Boever, Siska Croubels, Kristel Demeyere, Bart Lambrecht, Patrick de Backer, Evelyne Meyer

\section{To cite this version:}

Sandra de Boever, Siska Croubels, Kristel Demeyere, Bart Lambrecht, Patrick de Backer, et al.. FLOW CYTOMETRIC DIFFERENTIATION OF AVIAN LEUKOCYTES AND ANALYSIS OF THEIR INTRACELLULAR CYTOKINE EXPRESSION. Avian Pathology, 2010, 39 (01), pp.41-46. 10.1080/03079450903473574 . hal-00557320

\section{HAL Id: hal-00557320 https://hal.science/hal-00557320}

Submitted on 19 Jan 2011

HAL is a multi-disciplinary open access archive for the deposit and dissemination of scientific research documents, whether they are published or not. The documents may come from teaching and research institutions in France or abroad, or from public or private research centers.
L'archive ouverte pluridisciplinaire HAL, est destinée au dépôt et à la diffusion de documents scientifiques de niveau recherche, publiés ou non, émanant des établissements d'enseignement et de recherche français ou étrangers, des laboratoires publics ou privés. 


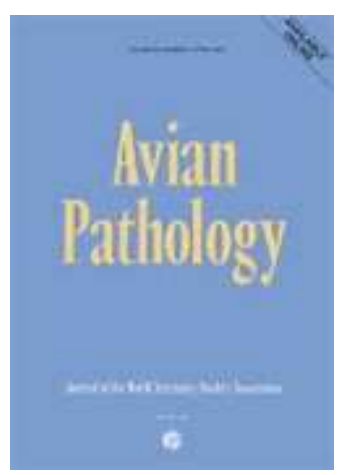

\section{FLOW CYTOMETRIC DIFFERENTIATION OF AVIAN LEUKOCYTES AND ANALYSIS OF THEIR INTRACELLULAR CYTOKINE EXPRESSION}

\begin{tabular}{|r|l|}
\hline Journal: & Avian Pathology \\
\hline Manuscript ID: & CAVP-2009-0074.R1 \\
\hline Manuscript Type: & Original Research Paper \\
\hline Date Submitted by the & $16-$ Sep-2009 \\
\hline Complete List of Authors: & $\begin{array}{l}\text { De Boever, Sandra; Faculty of Veterinary Medicine, Pharmacology, } \\
\text { Toxicology and Biochemistry } \\
\text { Croubels, Siska } \\
\text { Demeyere, Kristel } \\
\text { Lambrecht, Bart } \\
\text { De Backer, Patrick } \\
\text { Meyer, Evelyne }\end{array}$ \\
\hline Keywords: & \begin{tabular}{l} 
chicken, leukocyte identification, CD45, cytokine expression \\
\hline
\end{tabular} \\
\hline
\end{tabular}

\section{SCHOLARONE ${ }^{\text {IN }}$ Manuscripts}


Flow cytometric differentiation of avian leukocytes and analysis of their intracellular cytokine expression

\section{S. De Boever ${ }^{1 *}$, S. Croubels ${ }^{1}$, K. Demeyere ${ }^{1}$, B. Lambrecht ${ }^{2}$, P. De Backer ${ }^{1}$, E. Meyer $^{1}$}

${ }^{1}$ Department of Pharmacology, Toxicology and Biochemistry, Faculty of Veterinary

Medicine, Ghent University, Salisburylaan 133, 9820 Merelbeke, Belgium

${ }^{2}$ Department of Internal Medicine, Faculty of Medicine and Health Science, Ghent University,

De Pintelaan 185, 9000 Ghent, Belgium

Short title: Flow cytometric analysis of avian leukocytes

*Author to whom correspondence should be addressed:

sandra.deboever@ugent.be Tel.: 0032-9-264.73.24 Fax.: 0032-9-264.74.97

Received: 29 July 2009 


\section{Abstract}

A flow cytometric method for the identification of chicken blood leukocyte subpopulations and thrombocytes was developed. An anti-chicken CD45 phycoerythrin-labelled antibody was used to distinguish leukocytes from red blood cell nuclei. Leukocytes and thrombocytes were identified using a combination of their CD45-positivity and their typical side scatter properties. The identity of the CD45-positive cells was confirmed by sorting the subpopulations and subsequent light microscopic evaluation.

In these differentiated cell populations, intracellular expression analysis of the proinflammatory cytokines interleukin-1 $\beta$ and IL-6 was subsequently optimised on whole blood after in vitro stimulation with lipopolysaccharide from Escherichia coli strain O127:B8.

\section{Introduction}

Flow cytometry is a preferred method to phenotype ex vivo derived individual leukocytes from various species (Bohls et al., 2006). The flow cytometric differentiation of avian leukocytes has been described for monocytes (Mast et al., 1998), lymphocyte subpopulations (Fair et al., 2008) and thrombocytes (Viertlboeck and Göbel, 2007). Uchiyama et al. (2005) used anon-specific fluorescent lipophilic dye $\mathrm{DiOC}_{6}(3)$ for differentiation and counting of quail and chicken blood cells.

In mammals, the common leukocyte antigen CD45 is a haemopoietic cell-specific surface glycoprotein with a cytoplasmic tyrosine phosphatase domain that is believed to play a role in $\mathrm{T}$ - and B cell receptor signal transduction (Tchilian and Beverly, 2006). Various isoforms are expressed on different types of lymphohematopoietic cells, while it is absent on 
mammalian platelets and mature erythrocytes. The avian CD45 homolog is expressed on all chicken leukocytes but not on erythroid cells (Paramithiotis et al., 1991). Chicken thrombocytes, which are the equivalent of mammalian platelets, also express the CD45 antigen although at consistently lower levels compared to lymphocytes (Horiuchi et al., 2004; Viertlboeck and Göbel, 2007).

Avian heterophils, which are the equivalent of mammalian neutrophils, blood monocytes, and thrombocytes, release a cascade of cytokines upon stimulation with various infectious or non-infectious agents such as lipopolysaccharide (LPS) (Rhind et al., 2001; Kogut et al., 2005; Scott et al., 2008; Ferdous et al., 2008). LPS is commonly used to induce an acute phase reaction in humans and animals because of its proinflammatory properties (Skarnes et al., 1981; Klosterhalfen et al., 1992; Erroi et al., 1993; Franco et al., 2000; Maxwell et al., 2002; De Boever et al., 2008). LPS interacts with the innate immune system through Toll-like receptor 4 (TLR4), a member of the family of cell-surface and endosomally expressed receptors that recognize conserved molecular patterns unique to microorganisms (Palsson-Mcdermott and O'Neill, 2004; Janssens and Beyaert, 2003). Recognition of microbial components by TLRs triggers a cascade of cellular signals that culminates in the activation of Nuclear Factor $-\kappa \mathrm{B}$ which leads to inflammatory gene expression (Verstrepen $e t$ al., 2008). Acute endotoxemia represents a tool for gaining insight into inflammatory processes (Remick and Ward, 2005). Furthermore, such a controlled inflammation model is of interest to test the pharmacodynamic properties of anti-inflammatory drugs. To be able to monitor the progress of the inflammatory response and evaluate the immune-modulatory effect of anti-inflammatory drugs, several parameters can be determined including body temperature, blood pressure, cytokine expression and the production of acute phase proteins. Of relevance in this context is that the cytokines IL-1 $\beta$ and IL- 6 have been characterized as major endogenous pyrogens or fever-inducers using several animal models (Kluger, 1991; 
Jakab and Kalabay, 1998; Leon et al., 1999). Flow cytometry is a powerful analytical technique allowing the quantitative assessment of cytokine production at the single cell level. Using multiple colour-labelling, the simultaneous identification of different selected parameters can be performed (Bueno et al., 2001; Schultz et al., 2002; Schuerwegh et al., 2003).

In this report we describe a flow cytometric method for the identification of avian Deleted: paper leukocyte subpopulations and thrombocytes based on their combined CD45 positivity and side scatter properties. The major advantage of this technique is the use of a single antibody directed against a common leukocyte antigen for the identification of the leukocyte subpopulations and thrombocytes. Furthermore, intracellular detection of IL-1 $\beta$ and IL-6 was performed in these different leukocyte subpopulations. This new tool allows us to monitor the cytokine expression after in vivo LPS administration in broiler chickens.

\section{Materials and Methods}

Blood samples. Blood samples $(0.5 \mathrm{ml})$ were collected from the leg vein from laying hens, kept as blood donors, into heparin containing tubes (Venoject , Terumo Corp., Tokyo, Japan). This procedure was approved by the Ethics committee of the Faculty of Veterinary Medicine (EC 2006/035)

Reagents and antibodies. The phycoerythrin (PE) conjugated Cell Lab mouse monoclonal anti-chicken CD45 antibody, isotype IgM $\kappa$ was purchased from Analis (Gent, Belgium). Two polyclonal IgG antibodies, both raised in rabbits and directed against chicken IL-1 $\beta$

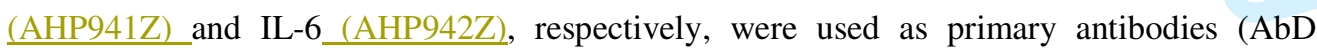


Serotec, Cergy Saint-Christophe, France). An allophycocyanin (APC)-conjugated fragment $\mathrm{F}\left(\mathrm{ab}^{\prime}\right)_{2}$ of a goat antibody to rabbit immunoglobulin (Santa Cruz biotechnology Inc., Heidelberg, Germany) was used as secondary antibody.

Goat serum, RPMI 1640 and bovine serum albumin (BSA) were purchased from Invitrogen (Merelbeke, Belgium). BD FACS Lysing solution, BD FACS Permeabilizing solution 2 and BD CellFIX were purchased from BD Biosciences (Erembodegem, Belgium).

LPS of Escherichia coli strain O127:B8 was purchased from Sigma-Aldrich (Bornem, Belgium).

Staining procedure and flow cytometric analysis. Chicken leukocytes and thrombocytes were obtained from whole blood after lysis of the erythrocytes. For this purpose, $4.5 \mathrm{ml}$ of BD FACS Lysing solution, 1/10 diluted in distilled water, was added to $0.5 \mathrm{ml}$ of blood in a Falcon tube for 10 minutes (min) at room temperature. After washing andcentrifugation for 5 min at $500 \mathrm{~g}$, the pellet was resuspended in $500 \mu 1$ RPMI and $50 \mu 1$ was pipetted into a flow cytometer tube. Following titration, testing 4, 6, 8, 10 and $20 \mu \mathrm{g} / \mathrm{ml}$ as concentrations, the PE-labelled anti-CD45 was added in a final concentration of $6 \mu \mathrm{g} / \mathrm{ml}$ and samples were incubated for $30 \mathrm{~min}$ at $4^{\circ} \mathrm{C}$.

For the in vitro stimulation with LPS, $0.5 \mathrm{ml}$ of whole blood was incubated with LPS at a final concentration of $10 \mu \mathrm{g} / \mathrm{ml}$ for 3 hours at $37^{\circ} \mathrm{C}$ in a shaking warm water bath (Memmert, Model WNB 14, Schwabad, Germany). Subsequently, erythrocytes were lysed and leukocytes and thrombocytes were labelled as described above, followed by permeabilization using BD FACS Permeabilizing solution 2, 1/10 diluted with distilled water, again for $10 \mathrm{~min}$ at room temperature. As for $\mathrm{CD} 45$, the optimal working dilutions for the primary antibodies directed against IL-1 $\beta$ and IL- 6 were also optimized by means of titration, testing 1.6, 3.3, 6.6, 10, 12.5, 25, 50 and $100 \mu \mathrm{g} / \mathrm{ml}$ as concentrations. A final concentration of 
$50 \mu \mathrm{g} / \mathrm{ml}$ was used and samples were incubated for $30 \mathrm{~min}$ at room temperature. Blocking was performed by adding $20 \%$ goat serum in RPMI for $30 \mathrm{~min}$ at room temperature. Finally, the APC-labelled secondary antibody was added at a concentration of $6 \mu \mathrm{g} / \mathrm{ml}$ for $30 \mathrm{~min}$ at $4^{\circ} \mathrm{C}$. Cells were resuspended in $450 \mu \mathrm{l}$ CellFIX, $1 / 10$ diluted with distilled water. The optimal antibody concentrations of the primary and secondary antibodies were also determined by titration.

Samples were analysed using a double laser bench top flow cytometer FACSCanto (Beckton Dickinson Biosciences) and the data were analysed with FACSDiva Software (Becton Dickinson). Excitation was performed with a $488 \mathrm{~nm}$ argon-ion laser and emission collected using a 530/30 nm band pass (BP) filter for FITC conjugates, a 585/42 nm BP filter for PE conjugates and a 660/20 nm BP filter for APC conjugates. Two basic parameters, i.e. the side scatter (SSC), which is proportional to the cellular granularity, and the forward scatter (FSC) which is proportional to cell size, were analyzed. For the CD45 expression, the amount of CD45 antigen present per cell (mean fluorescence intensity, MFI) was determined in all populations as presented in Figure 3 .

For the cytokine expression, the $\%$ of IL-1 $\beta$ and IL- 6 positive cells and their MFI were assessed after differentiation based on CD45 positivity and SSC as described above.

Additionally, flow cytometric cell sorting was performed on $\mathrm{CD} 45^{+}$cells (BD FACSAria II, California, USA). The sorted cell populations were stained (Diff-Quick, Acros Organics N.V., Geel, Belgium) after cytocentrifugation (Shandon, UK) and subsequent analysis of the slides by light microscopy (Olympus BX-UCB, Pennsylvania, USA).

The aim of this study was two-fold, i.e. to develop (1) a straightforward method to differentiate avian white blood cells and (2) to enable the subsequent assessment of their individual intracellular cytokine expression after LPS challenge. 


\section{Results and Discussion}

(1) Flow cytometric identification of avian monocytes (Mast et al., 1998), lymphocyte subpopulations (Bohls et al., 2006; Fair et al., 2008) and thrombocytes (Viertlboeck and Göbel, 2007) has already been performed. The non-specific fluorescent lipophilic dye $\mathrm{DiOC}_{6}(3)$ used by Uchiyama et al. (2005) for differentiation, was very useful for counting of quail and chicken blood cells. We succeeded in the development of a straightforward method to differentiate leukocyte subpopulations and thrombocytes using a single antibody directed against the common leukocyte antigen. The anti-CD45 antibody used in the current study allows a better discrimination between the leukocyte subpopulations. This is especially the case for lymphocytes and thrombocytes because of the reduced interference with the red blood cell nuclei. The presence of nucleated erythrocytes and thrombocytes was indeed a challenge as this is a major difference between mammalian and avian blood cells (Campbell and Ellis, 2007). Lysis of the erythrocytes was tested comparing a Tris-aminomethane/ $\mathrm{NH}_{4} \mathrm{Cl}$ buffer with the commercial lysing solution, with the latter giving the best results (data not shown). Nevertheless, after lysis, the red blood cell nuclei were still present and since their size is similar to that of a small lymphocyte, the discrimination between both events was not possible based on the commonly used FSC versus SSC dot-plot as illustrated in Figure 1 (A). However, the combined use of an anti-chicken CD45 antibody and the SSC, enabled the discrimination between lymphocytes and red blood cell nuclei. On the representative dot plot showing $\mathrm{CD}^{+} 5^{+}$cells versus SSC, the different subpopulations, i.e. lymphocytes, thrombocytes, monocytes and heterophils, could be gated (Figure $1 \mathrm{~B}$ ). The position of the different subpopulations on the dot plot is similar to that seen in mammalian species, except for thrombocytes, which are not present in mammalian blood (Figure $1 \mathrm{C}$ ).

Deleted: the 
The optimal concentration of the anti-CD45 antibody $(6 \mu \mathrm{g} / \mathrm{ml})$ was determined by titration (data not shown).

To confirm the identity of the gated populations on the anti CD45-PE versus SSC dotplot, additional sorting was performed, followed by light microscopy (Figure 2). Population L was composed of lymphocytes, characterized by a round nucleus and weakly basophilic cytoplasm. Population M, contains monocytes with the hallmarks of being the largest leukocytes and having a large nucleus. The heterophils (population $\mathrm{H}$ ) are characterized by a lobed nucleus and abundant eosinophilic granules in the cytoplasm. For the heterophils and lymphocytes, a purity of $96 \%$ and $89.4 \%$ could be calculated, respectively. For the monocytes and thrombocytes no percentages can be provided as only a few cells were present on the slide.

(2) In a second series of experiments the optimized cell differentiation method was combined with intracellular detection of pro-inflammatory cytokines. More specifically, IL$1 \beta$ and IL- 6 were chosen since these cytokines have been implicated as key mediators of fever (Kluger, 1991; Jakab and Kalabay, 1998; Leon et al., 1999). Commercial antibodies directed against chicken IL-1 $\beta$ and IL-6 are of polyclonal origin and have not yet been tested for flow cytometry. In the current experiment, the method was optimized after in vitro stimulation of heparin-treated whole blood samples with LPS, because cell activation has been reported to be better and cytokine expression is more efficient than with other anticoagulants (Coló Brunialti et al., 2002). Both a commercial lysing agent, BD FACS Lysing solution and a tris$\underline{\text { aminomethane } / \mathrm{NH}_{4}} \underline{\mathrm{Cl}}_{\mathrm{Cl}}$ buffer were tested, with the former giving the best results. It should be remarked that we deliberately chose not to use a secretion block in the in vitro experiments, to mimic the in vivo situation as closely as possible. Moreover, the use of a fixation-containing lysing agent in the first step of the protocol, prevents cytokine secretion after sampling. 
Several amounts of the commercial permeabilizing solution were tested, with $500 \mu \mathrm{l}$ resulting in the highest percentage of cytokine expressing cells and the highest MFI (data not shown). As for CD45, the optimal working dilutions for the primary antibodies directed against IL-1 $\beta$ and IL-6 were also optimized by means of titration (data not shown). An APClabeled secondary antibody was chosen for intracellular cytokine detection. APC belongs to a family of phycobiliproteins with a broad excitation spectrum and a large Stoke's shift with a high quantum yield fluorescence (Jung and Dailey, 1989; Telford et al., 2001). The optimal concentration of the secondary antibody was also determined by titration.

A fluorescein isothiocyanate (FITC) labelled antibody was first tested as secondary antibody, but since preliminary data confirmed that FITC stains the cytoplasmic granules of avian heterophils (Rath et al., 1998), this fluorochrome was not suited for intracellular cytokine detection nor could FITC-labelled antibodies be used for the identification of the different leukocyte subpopulations.

After stimulation of whole blood with LPS, cytokine production was measured in the leukocyte subpopulations and thrombocytes as illustrated in Figure 3. The MFI of LPSstimulated cells for both cytokines is shown in Table 1. On the dot plot of samples for which only the CD45-PE antibody and the secondary APC-labelled antibody were added (Figure 3 A), a grid was placed to be able to discriminate between specific and non-specific staining of the secondary antibody. As could be expected from literature (Schultz et al., 2002; Schuerwegh et al., 2003), stimulation with LPS evoked a right-shift of the populations, indicating the intracellular presence of IL-1 $\beta$ and IL-6. Monocytes showed the largest shift, both for IL-1 $\beta$ and IL-6. Thrombocytes are also capable of synthesizing cytokines. This observation is in accordance with Scott et al. (2007) and Ferdous et al. (2008), although in those experiments IL-1 $\beta$ and IL-6 expression was measured at the mRNA level. Heterophils expressed the lowest level of cytokines, although mRNA expression of cytokines by these

Deleted: the

\begin{tabular}{l} 
Deleted: \\
Deleted: to \\
\hline Deleted: as
\end{tabular}

Deleted: The $\mathrm{h}$ 
cells after LPS stimulation has been, reported (Kogut et al., 2005). However, the latter authors mention that mRNA levels do not necessarily equate to bioactive protein. A confocal microscopic image of a lymphocyte expressing IL-6 is shown in Figure 2B.

Finally, it should be remarked that heterophils clearly expressed more CD45 molecules after LPS stimulation (data not shown). This observation corroborates findings in human granulocytes that contain an intracellular pool of CD45 and upon stimulation with formylmethionylleucylphenylalanine, ionophore A23187 or LPS increase the surface expression of CD45 (Lacal et al., 1988; Caldwell et al., 1991; Stie and Jesaitis, 2007).

In conclusion, we developed a straightforward method for the differentiation of the different leukocyte subpopulations in avian blood, using a monoclonal antibody directed Deleted: ies against chicken CD45 in combination with SSC properties. Furthermore, intracellular IL-1 $\beta$ and IL-6 expression in these individual populations was assessed. This method can now be applied for the detection of intracellular cytokine expression after intravenous administration of LPS to broiler chickens.

\section{Acknowledgements}

The authors would like to thank E. Neirinckx, D. De Clercq and K. Jonckheere for the help with the animal experiment. 


\section{References}

Bohls, R.L., Smith, R., Ferro, P.J., Silvy N.J., Li, Z., Collison E.W. (2006). The use of flow cytometry to discriminate avian lymphocytes from contaminating thrombocytes. Developmental and Comparative Immunology, 30, 843-850.

Bueno, C., Almeida, J., Alguero M.C., Sànchez, M.L., Vaquero, J.M., Laso, F.J., San Miguel, J.F., Escribano, L., Orfao, A. (2001). Flow cytometric analysis of cytokine production by normal human peripheral blood dendritic cells and monocytes: comparative analysis of different stimuli, secretion-blocking agents and incubation periods. Cytometry, 46, $33-40$.

Caldwell, C.W., Patterson, W.P., Yesus, Y.W. (1991). Translocation of CD45RA in neutrophils. Journal of Leukocyte Biology, 49, 317-328.

Campbell, T.W., Ellis, C.K. (2007). Avian \& exotic animal hematology \& cytology, Third edn (320 pp). Carlton: Blackwell Publishing.

Coló Brunialti, M.K., Kallás, E.G., Freudenberg, M., Galanos, C., Salomao, R. (2002). Influence of EDTA and heparin on lipopolysaccharide binding and cell activation, evaluated at single-cell level in whole blood. Cytometry, 50, 14-18.

De Boever, S., Beyaert, R., Vandemaele, F., Baert, K., Duchateau, L., Goddeeris, B., De Backer, P., Croubels, S. (2008). The influence of age and repeated lipopolysaccharide administration on body temperature and the concentration of interleukin-6 and IgM antibodies in broiler chickens. Avian Pathology, 37, 39-44.

Erroi, A., Fantuzzi, G., Mengozzi, M., Sironi, M., Orencole, S.F., Clark, B.D., Dinarello, C.A., Isetta, A., Gnocchi, P., Giovarelli, M., Ghezzi, P. (1993). Differential regulation of cytokine production in lipopolysaccharide tolerance in mice. Infection and Immunology, 61, 4356-4359. 
Fair, J.M., Taylor-McCabe, K.J., Shou, Y., Marrone, B.L. (2008). Immunophenotyping of chicken peripheral blood lymphocyte subpopulations: Individual variability and repeatability. Veterinary Immunology and Immunopathology, 125, 286-273.

Ferdous, F., Maurice, D., Scott, T. (2008). Broiler chick thrombocyte response to lipopolysaccharide. Poultry Science, 87, 61-63.

Franco, R.F., de Jonge, E., Dekkers, P.E.P., Timmerman, J.J., Spek, C.A., van Deventer, S.J.H., van Deursen, P., van Kerkhoff, L., van Gemen, B., ten Cate, H., van der Poll, T., Reitsma, P.H. (2000). The in vivo kinetics of tissue factor messenger RNA expression during human endotoxemia: relationship with activation of coagulation. Blood, 96, 554559.

Horiuchi, H., Tanaka, K., Shigata, A., Yoshida, K., Kushima, K., Ohta, H., Furusawa, S., Matsuda, H. (2004). A monoclonal antibody against chicken thrombocytes reacts with the cells of thrombocyte lineage. Immunolology, 66, 243-250.

Janssens, S. \& Beyaert, R. (2003). Role of Toll-like receptor in pathogen recognition. Clinical Microbiology Reviews, 16, 637-646.

Jakab, L., Kalabay, L. (1998). The acute phase reaction syndrome: the acute phase reactants. Acta Microbiologica et Immunologica Hungarica, 45, 409-418.

Jung, T.M., Dailey, M.O. (1989). A novel and inexpensive source of allophycocyanin for multicolour flow cytometry. Journal of Immunological Methods, 121, 9-18.

Klosterhalfen, B., Hörstmann-Jungemann, K., Vogel, P., Flohé, S., Offner, F., Kirkpatrick, C.J., Heinrich, P.C. (1992). Time course of various inflammatory mediators during recurrent endotoxemia. Biochemical Pharmacology, 43, 2103-2109.

Kluger, M. (1991). Fever: role of pyrogens and cryogens. Physiological Reviews, 14, 93-127. 
Kogut, M.H., Iqbal, M., He, H., Philbin, V., Kaiser, P., Smith, A. (2005). Expression and function of Toll-like receptors in chicken heterophils. Developmental and Comparative Immunology, 29, 791-807.

Lacal, P., Pulidos, R., Sànchez-Madrid, F., Mollinedo, F. (1988). Intracellular location of T200 and Mol glycoproteins in human neutrophils. Journal of Biological Chemistry, 20, 9946-9951.

Leon, L.R., Kozak, W., Rudolph, K., Kluger, M.J. (1999). An antipyretic role for interleukin 10 in LPS fever in mice. American Journal of Physiology, 276, R81-89.

Mast, J., Goddeeris, B., Peeters, K., Vandesande, F., Berghman, L. (1998). Characterization of chicken monocytes, macrophages and interdigitating cells by the monoclonal antibody KUL01. Veterinary Immunology and Immunopathology, 61, 343-357.

Maxwell, J.R., Ruby, C., Kerkvliet, N.I., Vella, A.T. (2002). Contrasting the role of costimulation and the natural adjuvant lipopolysaccharide during the induction of $\mathrm{T}$ cell immunity. Journal of Immunology, 168, 4372-4381.

Pålsson-McDermott, E. \& O’Neill, L. (2004). Signal transduction by the lipopolysaccharide receptor, Toll-like receptor-4. Immunology, 113, 153-162.

Paramithiotis, E., Tkalec, L., Ratcliffe, J.H. (1991). High levels of CD45 are co-ordinately expressed with CD4 and CD8 on avian thymocytes. Journal of Immunology, 11, 37103717.

Rath, N.C., Huff, G.R., Balog, J.M., Huff, W.E. (1998). Fluorescein isothiocyanate staining and characterization of avian heterophils. Veterinary Immunology and Immunopathology, 64, 83-95.

Remick, D.G., Ward, P.A. (2005). Evaluation of endotoxin models for the study of sepsis. Shock, 24, 7-11. 
Rhind, S.G., Castellani, J.W., Brenner, I.K.M., Shephard, R.J., Zamecnik, J., Montain, S.J., Young, A.J., Shek, P.N. (2001). Intracellular monocyte and serum cytokine expression is modulated by exhausting exercise and cold exposure. American Journal of Physiology Regulatory, Integrative and Comparative Physiology, 281, R66-R75.

Schuerwegh, A., De Clerck, L., Bridts, C., Stevens, W. (2003). Comparison of intracellular cytokine production with extracellular cytokine levels using two flow cytometric techniques. Cytometry Part B, 55B, 52-58.

Schultz, C., Rott, C., Temming, P., von Puttkammer, J., Bucsky, P. (2002). Influence of specimen age and use of different negative controls in determination of intracytoplasmic levels of cytokines after whole-blood culture assay. Clinical Diagnostic Laboratory Immunology, 9, 295-298.

Scott, T., Owens, M.D. (2008). Thrombocytes respond to lipopolysaccharide through Tolllike receptor-4, and MAP kinase and NF- $\kappa \mathrm{B}$ pathways leading to expression of interleukin 6 and cyclooxygenase-2 with production of prostaglandin E2. Molecular Immunology, 45, 1001-1008.

Skarnes, R.C., Brown, S.K., Hull, S.S., McCracken, J.A. (1981). Role of prostaglandin E in the biphasic fever response to endotoxin. Journal of Experimental Medecine, 154, 12121224.

Stie, J., Jesaitis, A.J. (2007). Reorganization of the human neutrophil plasma membrane is associated with functional priming: implications for neutrophil preparations. Journal of Leukocyte Biology, 81, 672-685.

Tchilian, E.Z., Beverly, P.C.L. (2006). Altered CD45 expression and disease. TRENDS in Immunology, 27, 146-153. 
Telford, W.G., Moss, M.W., Morseman, J.P., Allnutt, F.C. (2001). Cryptomonad algal phycobiliproteins as fluorochromes for extracellular and intracellular antigen detection by flow cytometry. Cytometry, 44, 16-23.

Uchiyama, R., Morimoto, T., Kai, O., Uwatoko, K., Inoue, Y., Nakanishi, T. (2005). Counting absolute number of lymphocytes in quail whole blood by flow cytometry. Avian Pathology, 67, 441-444.

Verstrepen, L., Bekaert, T., Chau, T., Tavernier, J., Chariot, A. \& Beyaert, R. (2008). TLR-4, IL-1R, TNF-R signalling to NF-kappaB: variations on a common theme. Cellular and Molecular Life Science, 65, 2965-2978.

Viertlboeck, B.C., Göbel, T.W. (2007). Chicken thrombocytes express the CD51/CD61 integrin. Veterinary Immunology and Immunopathology, 119, 137-141. 


\section{Figure Legends:}

Figure 1: (A) Representative flow cytometrical SSC versus FSC dot plot of chicken blood after red blood cell lysis, without CD45 labelling, (B) representative flow cytometrical anti CD45-PE versus SSC dot-plot of a chicken blood sample after lysis of the erythrocytes ( $L$ : lymphocytes, TH: thrombocytes, $M$ : monocytes and H: Heterophils), (C) representative flow cytometrical SSC versus FSC dot-plot showing the populations gated on dot-plot B

Figure 2 (A): Microscopic image of sorted lymphocytes (L), monocytes (M) and heterophils (H) after Diff-Quick staining, (B) a confocal microscopic image of a lymphocyte expressing IL-6 (white arrow) surrounded by red blood cell nuclei. The secondary antibody was labeled with Alexa 488 and propidium iodide was used to stain the nucleus.

Figure 3: Representative flow cytometrical dot-plots of in vitro stimulated heterophil (H), monocyte (M), thrombocyte (TH) and lymphocyte (L) populations (A) after addition of antiCD45 PE and of the secondary APC-labelled antibody without the primary IL antibodies; (B) addition of anti-CD45 PE, the primary antibody directed against IL-1 $\beta$ and the secondary APC-labelled antibody; (C) addition of anti-CD45 PE labelled antibody, the primary antibody directed against IL-6 and the secondary APC-labelled antibody. Autofluorescence was consistently lower than $10^{2}$ for all samples. The mean \% of positive events \pm standard error of the mean $(n=6)$ is indicated in the upper right quadrants.
Deleted: Figure 2: Microscopic image of sorted lymphocytes $(L)$, monocytes (M) and heterophils (H) after DiffQuick staining $\mathbb{\|}$

Deleted: Figure 3: Representative flow cytometrical dot-plots of in vitro stimulated heterophil $(\mathbf{H})$, monocyte (M), thrombocyte (TH) and lymphocyte (L) populations (A) after addition of anti-CD45 PE and of the secondary APC-labelled antibody without the primary IL antibodies; (B) addition of anti-CD45 PE, the primary antibody directed against IL-1 $\beta$ and the secondary APC-labelled antibody; (C) addition of anti-CD45 PE labelled antibody, the primary antibody directed against IL-6 and the secondary APC-labelled antibody. secondary APC-labelled antibody.
Autofluorescence was consistently lower than $\mathbf{1 0}^{2}$ for all samples. II 
Table 1: Mean Fluorescence Intensity (MFI) ( \pm standard error of the mean) for the different cell types stained for IL-1 $\beta$ and IL6 $(n=6)$

\begin{tabular}{lcc}
\hline & IL-1 $\boldsymbol{\beta}$ & IL-6 \\
\cline { 2 - 3 } Lymphocytes & $1800.8( \pm 246.6)$ & $1713.8( \pm 209.2)$ \\
Thrombocytes & $2465.5( \pm 303.9)$ & $2348.2( \pm 218.6)$ \\
Monocytes & $4297.0( \pm 361.4)$ & $3689.5( \pm 200.3)$ \\
Heterophils* & $11987.2( \pm 521.8)$ & $11796.8( \pm 489.7)$ \\
\hline
\end{tabular}

* The MFI values of the heterophils should be interpreted with caution due to the low $\%$ of cytokine expressing cells as shown in Figure 3. 

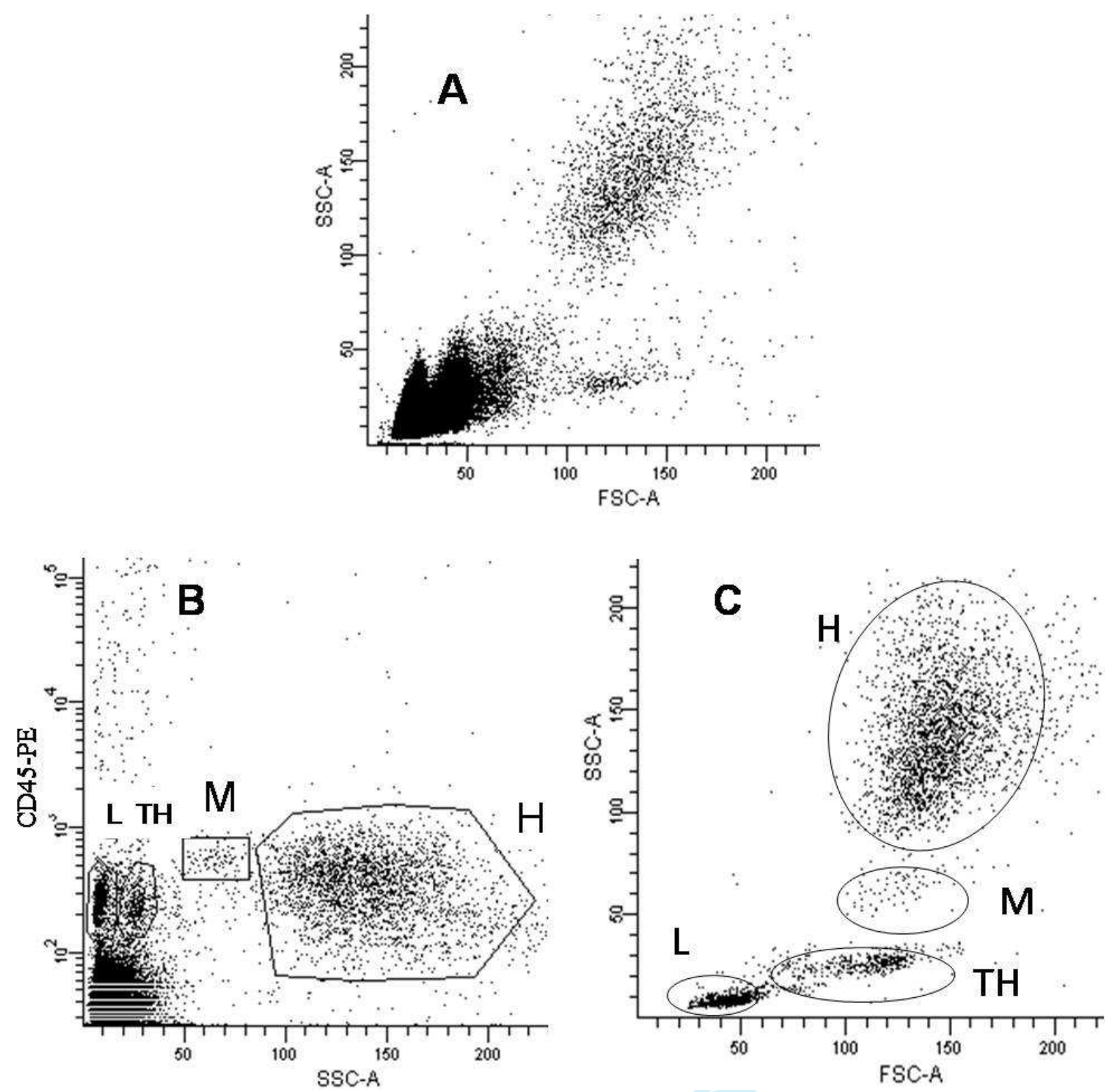

Figure 1: (A) Representative flow cytometrical SSC versus FSC dot plot of chicken blood after red blood cell lysis, without CD45 labelling, (B) representative flow cytometrical anti CD45-PE versus SSC dot-plot of a chicken blood sample after lysis of the erythrocytes (L: lymphocytes, TH: thrombocytes, M: monocytes and H: Heterophils), (C) representative flow cytometrical SSC versus FSC dot-plot showing the populations gated on dot-plot B 

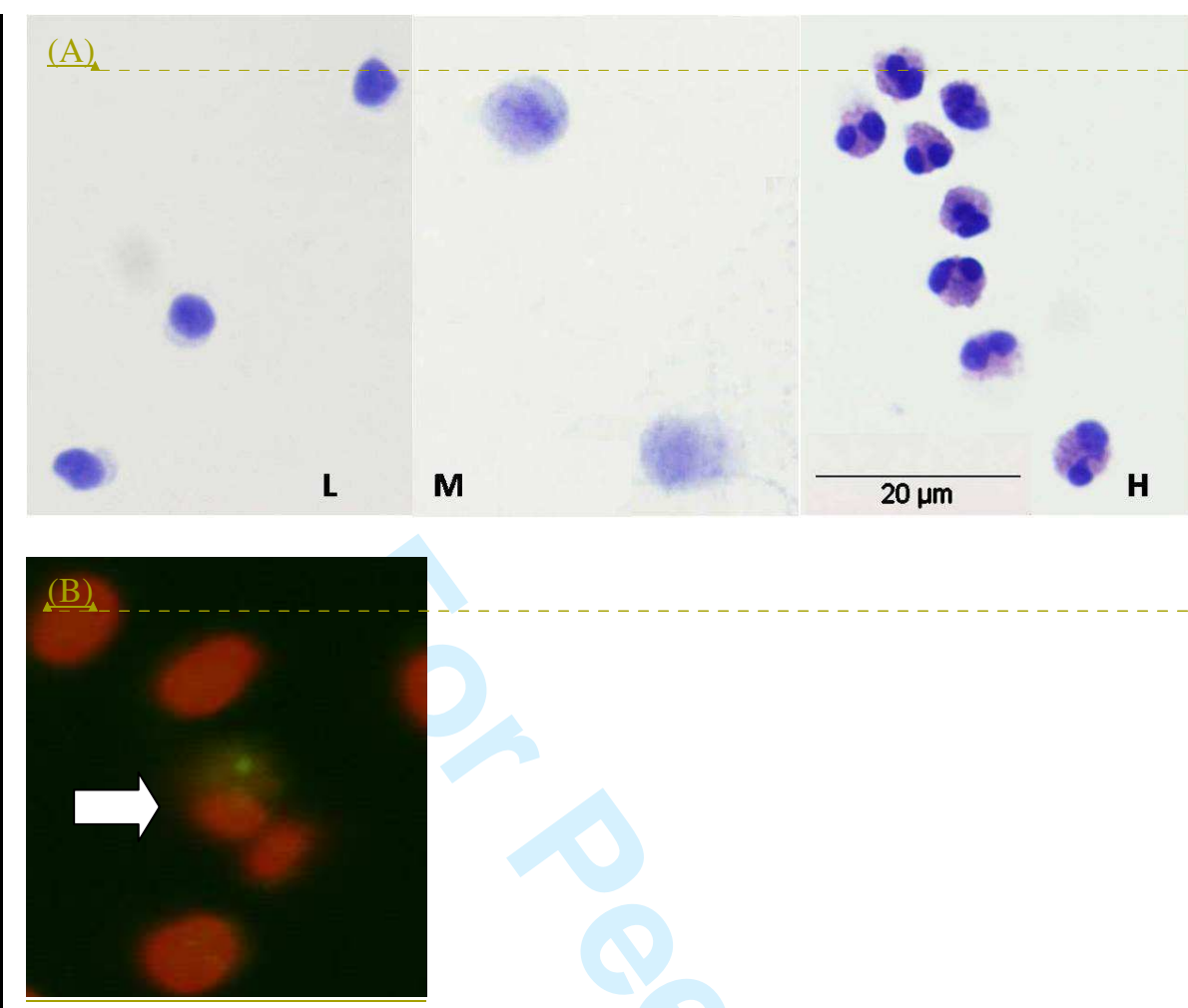

Formatted: Font color: White Formatted: Font color: White, Dutch (Belgium)

Figure 2 (A): Microscopic image of sorted lymphocytes (L), monocytes (M) and heterophils (H) after Diff-Quick staining, (B) a confocal microscopic image of a lymphocyte expressing $\underline{\text { IL-6 (white arrow) surrounded by red blood cell nuclei. The secondary antibody was labeled }}$ with Alexa 488 and propidium iodide was used to stain the nucleus. 
$A$

L

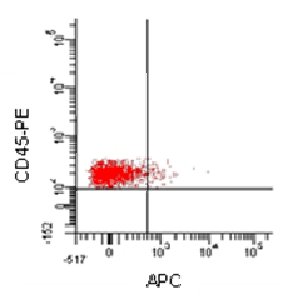

TH

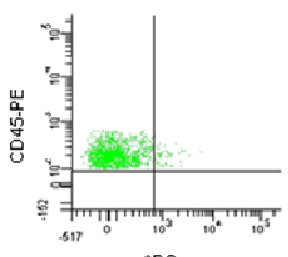

$\mathrm{M}$

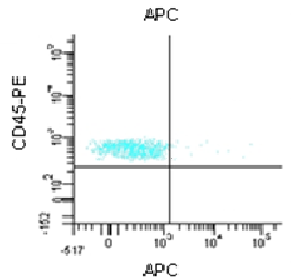

$\mathrm{H}$

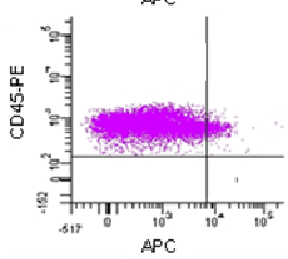

B
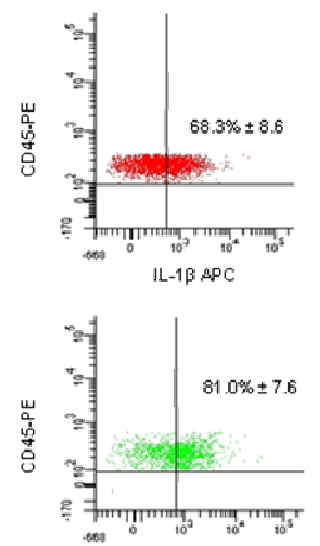

$\mathrm{IL}-1 \beta A \mathrm{APC}$
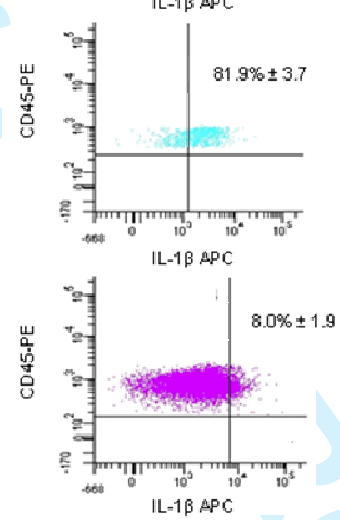

C.
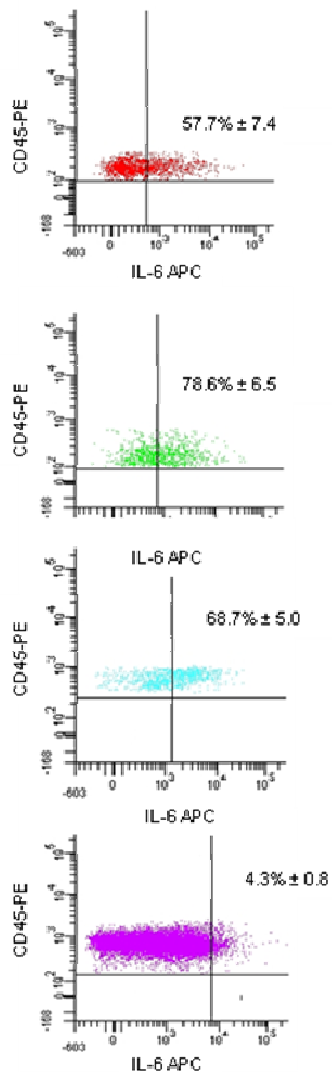

Deleted: $<$ sp $><$ sp $><$ sp $><$ sp $><$ sp $>$

A

$\mathrm{L}$

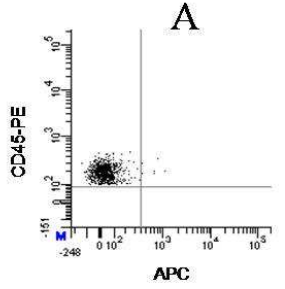

$\mathrm{TH}$
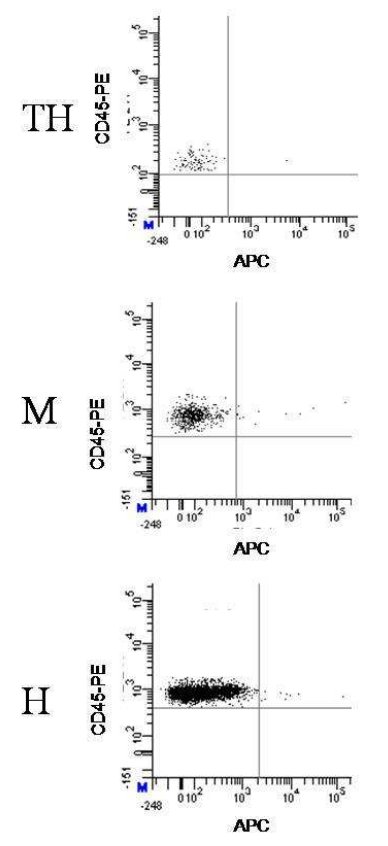

Figure 3: Representative flow cytometrical dot-plots of in vitro stimulated heterophil $(\mathrm{H})$, monocyte (M), thrombocyte (TH) and lymphocyte (L) populations (A) after addition of antiCD45 PE and of the secondary APC-labelled antibody without the primary IL antibodies; (B) addition of anti-CD45 PE, the primary antibody directed against IL- $1 \beta$ and the secondary APC-labelled antibody; (C) addition of anti-CD45 PE labelled antibody, the primary antibody directed against IL-6 and the secondary APC-labelled antibody. Autofluorescence was consistently lower than $10^{2}$ for all samples. The mean $\%$ of positive events \pm standard error of the mean $(\mathrm{n}=6)$ is mentioned in the upper right quandrants. 
Table 1: Mean Fluorescence Intensity (MFI) ( \pm standard error of the mean) for the different cell types for IL-1 $\beta$ and IL6 $(n=6)$

\begin{tabular}{lcc}
\hline & IL-1 $\boldsymbol{\beta}$ & IL-6 \\
\cline { 2 - 3 } Lymphocytes & $1800.8( \pm 246.6)$ & $1713.8( \pm 209.2)$ \\
Thrombocytes & $2465.5( \pm 303.9)$ & $2348.2( \pm 218.6)$ \\
Monocytes & $4297.0( \pm 361.4)$ & $3689.5( \pm 200.3)$ \\
Heterophils* & $11987.2( \pm 521.8)$ & $11796.8( \pm 489.7)$ \\
\hline
\end{tabular}

* The MFI values of the heterophils should be interpreted with caution due to the low $\%$ of cytokine expressing cells as shown in Figure 3. 


\section{REVISION NOTE MANUSCRIPT ID CAVP-2009-0074}

\section{Answer to the editor:}

We would like to thank the editor and the three reviewers for their constructive remarks, which were of great help to improve this methodological manuscript. Please find below a point-by-point list of answers to the issues raised.

Concerning the specific comments of the editor, following arguments can be provided:

- the main concern raised by reviewers \#1 and \#2 regarding the need for an appropriate negative control has been addressed by showing that an isotype control (polyclonal antibody, ab) does not cause a positive signal. Nevertheless, based on our arguments outlined in detail to both these reviewers, we propose to include the additional control results for the selective intracellular localization but not those for the isotype control in the revised manuscript, unless decided otherwise by the editor.

- we agree that lymphocytes are not the main producer of IL-1beta and IL-6. However, according to our experimental findings and literature, lymphocytes are indeed capable of producing both these cytokines. Our flow cytrometric observations were supported by confocal microscopy after stimulation of whole blood with LPS. Cell nuclei were stained using propidium iodide (PI), an Alexa 488-labeled secondary ab was used for visualizing IL-1 $\beta /-6$. Leukocyte differentiation was based on the nuclear morphology and cell size. A representative image (Figure $2 \mathrm{~B}$ ) is now included in the revised manuscript illustrating the intracellular staining of chicken lymphocytes for both cytokines.

- the data in the original Figure 3 were indeed not quantitative. To illustrate that our results were confirmatory, the $\%$ of positive events expressed as mean \pm standard deviation $(\mu \pm$ $\mathrm{SE}, \mathrm{n}=6$ ) are now provided in each of the upper right quadrants of the dot plots in the revised Figure 3 as requested. Moreover, the adequate reproducibility $(n=6)$ of our method is further illustrated in table 1 showing the mean fluorescence intensity (MFI) data $(\mu \pm \mathrm{SE})$ for each of the different cell types, both for IL-1 $\beta$ and IL-6. We preferred this format instead of the suggested bar graph because of space limitations. 
Answer to reviewers:

\section{Reviewer 1}

We would like to thank the reviewer for his/her constructive remarks which were of great help to improve this methodological manuscript.

- We fully agree with the main concern regarding the degree of non-specific binding of our primary polyclonal antibodies (abs). As suggested by the reviewer, two additional negative control experiments were carried out:

- A polyclonal isotype control (Rabbit IgG, EPITOMICS) was tested in the same concentration and under the same conditions as the primary polyclonal rabbit antichicken abs against IL-1 $\beta$ and IL-6. This isotype gave a low percentage of positive cells indicating the absence of non-specific binding, as shown in the dot-plots of LPS treated cells below.

Isotype
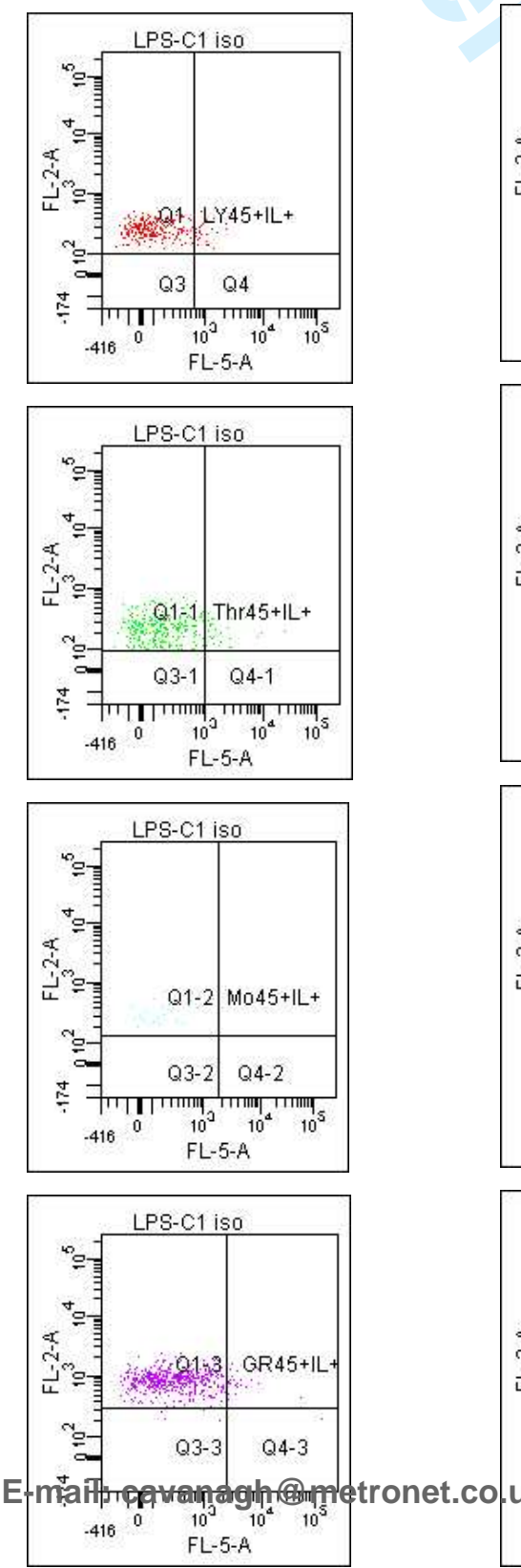

IL-6
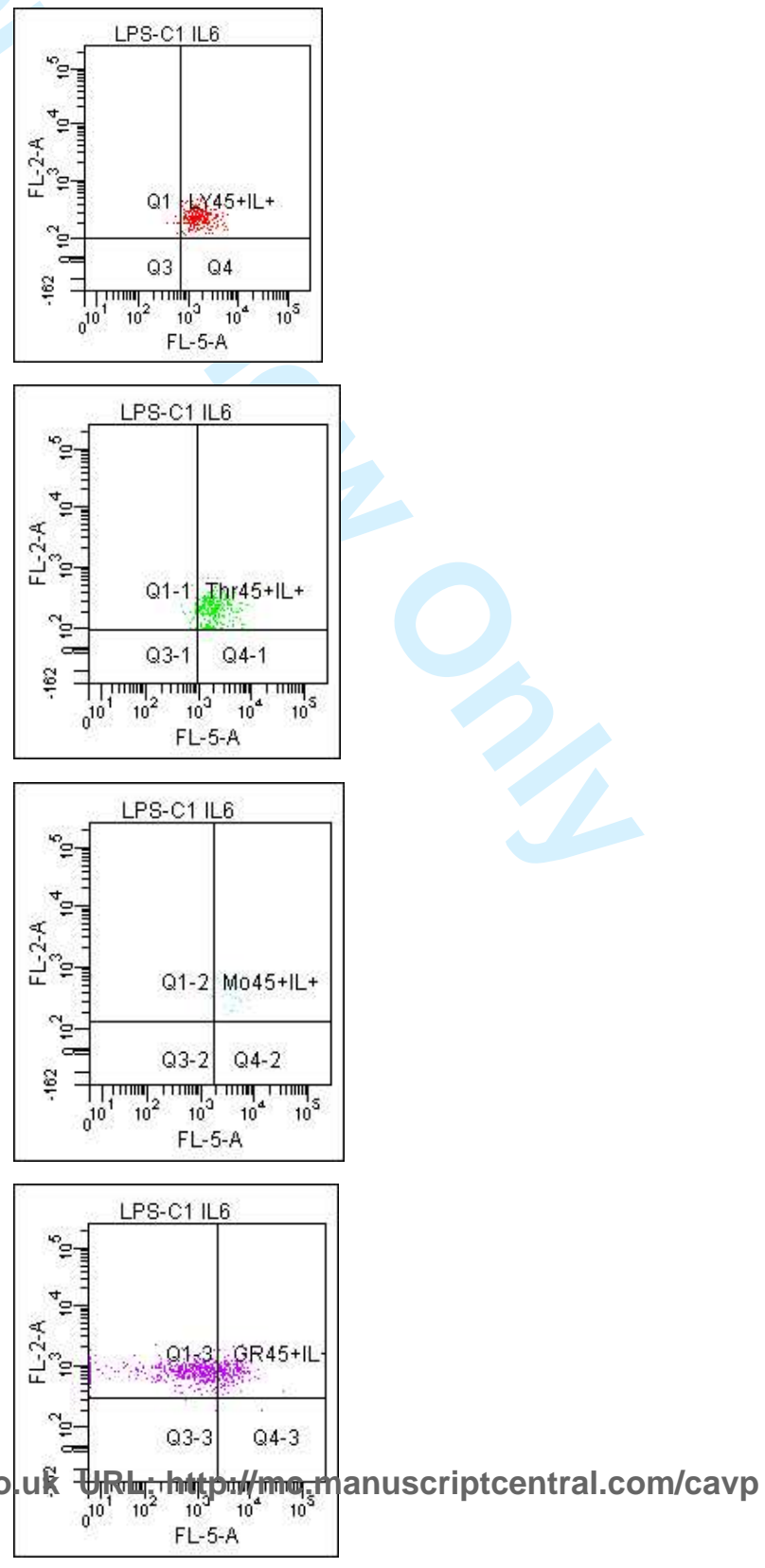
○ Staining of the LPS-treated cells without permeabilising solution was performed, but since the FACSlyse (Becton Dickinson, BD) solution used to lyse the red blood cells has already a significant permeabilization effect, these data could not be used as additional negative control. Indeed, the permeabilization step after incubation with the anti-CD45 antibodies is recommended by BD only to be sure that all cells are properly permeabilized. Therefore, an alternative control for the binding of our abs to the cell surface was carried out by confocal microscopy after stimulation of whole blood with LPS. Cell nuclei were stained using propidium iodide (PI), an Alexa 488-labeled secondary ab was used for visualizing IL-1 $\beta /-6$. Leukocyte differentiation was based on the nuclear morphology and cell size. A representative image (2B) is now included in the revised manuscript illustrating the intracellular staining of chicken lymphocytes for IL-6.

Although the results from both complementary negative control experiments are satisfactory, we propose to include only the confocal image showing the absence of cell surface binding of the abs in the revised manuscript. The reason not to include the isotype control results is that we are not convinced of the added value of this type of control to prove the absence of non-specific binding for our application. Following arguments motivate our decision: the company of the primary antibodies (Serotec) provided negative advice on the use of a polyclonal isotype ab, while the use of a monoclonal isotype is also not relevant; in general, the use of isotype controls remains to date highly controversial in the field of flow cytometry and recommended typically to test for non-specific binding of monoclonal abs in specific cell types (O'Gorman and Thomas, 1999, Isotype controls Time to let go? Cytometry; Hulspas et al., 2009, Considerations for the control of background fluorescence in clinical flow cytometry, Cytometry Part B: Clinical cytometry). To test our argumentation, we evaluated a second polyclonal isotype ab from the same class of immunoglobulin (i.e. $\operatorname{IgG}$ ) and at the same concentration but with only minor variations in characteristics compared to the first isotype in purification process and formulation. This second isotype yielded much much less satisfactory results (data not shown). 
We are aware that the high concentrations at which our primary abs were used increase the risk for non-specific binding, but we obtained these after appropriate titration of the abs. Addionally, preliminary results using chicken serum in an additional blocking step before labeling with our abs did not have any influence as shown below.
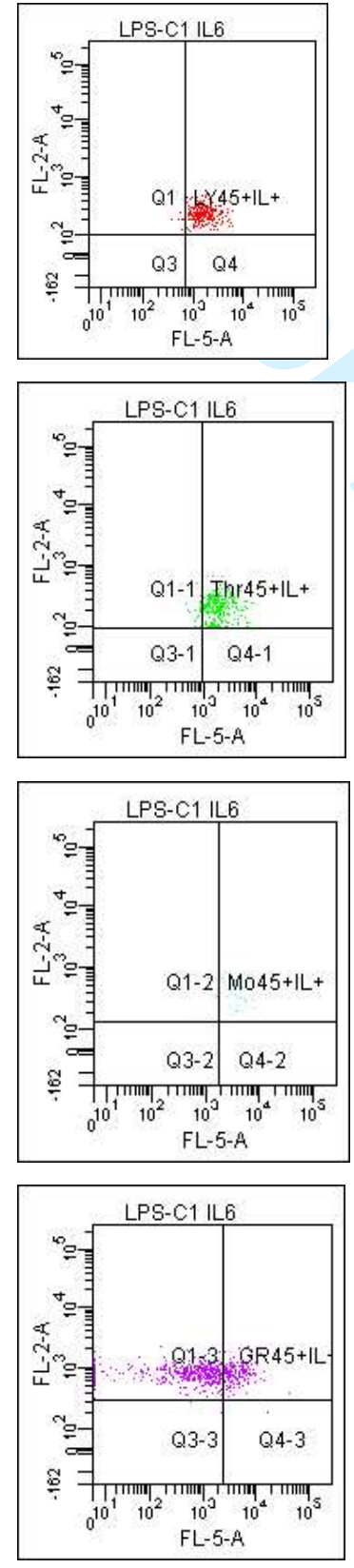

IL-6
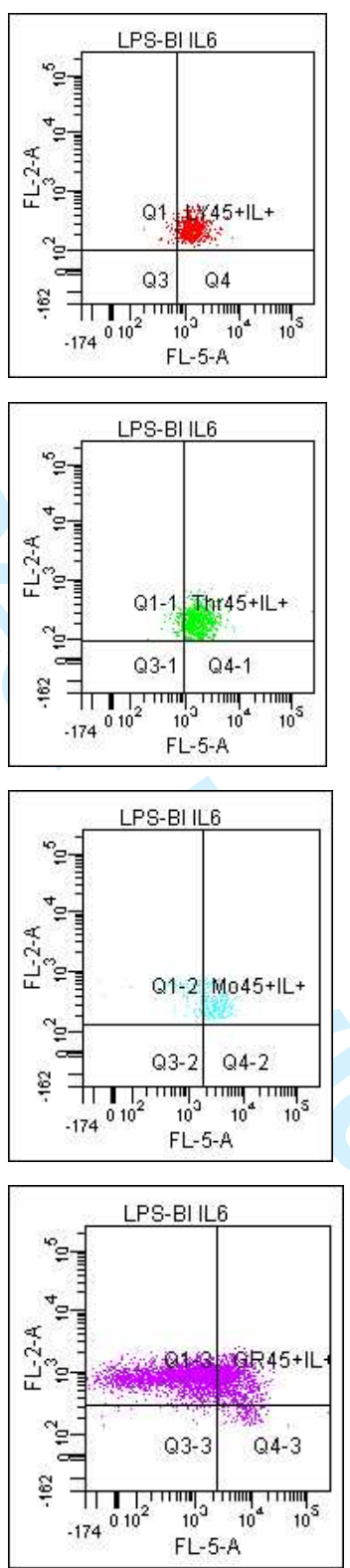

with blocking 
Also, autofluorescence and secondary ab controls were systematically used throughout the study. Finally, our in vivo study (De Boever et al., Avian Pathology, in press) shows a consistent increase for both cytokines in LPS- versus sham-inoculated animals in MFI but not in $\%+$ cells of heterophils which are typical candidates for non-specific binding after stimulation.

- High levels of LPS cause indeed cell death as correctly mentioned by the reviewer. Since the white blood cells are fixed and already partly permeabilized after lysis of the red blood cells by FACSlyse, these cells are dead and consequently stain positively with PI. Cell death of the white blood cells after contact with LPS in vivo was described in a former paper from our group (De Boever et al., Avian Pathology, in press), using Annexin-V to detect apoptosis.

\section{$\underline{\text { Reviewer } 2}$}

We would like to thank the reviewer for his/her constructive remarks which were of great help to improve this methodological manuscript.

- The reviewer remarked that the CD45 staining shown in Fig. 1 is low given that CD45 is an abundant cell surface antigen. In Fig. 3 the CD45 staining for the different cell types is indicated on the Y axis. This intensity of CD45 staining is in accordance with the findings of Paramithiotis et al. (1991), where the mean fluorescence intensity (MFI) values also vary between $10^{2}$ and $10^{3}$.

- The data on the \%CD45 + cells is indeed not shown, but the MFI can be determined from Fig. 3. The sentence was rephrased in the text. 
- We fully agree with the reviewer's remark regarding the technically demanding aspect of intracellular cytokine staining. As requested, the degree of non-specific binding of our primary polyclonal antibodies (abs) was evaluated by carrying out additional negative control experiments:

- A polyclonal isotype control (Rabbit IgG, EPITOMICS) was tested in the same concentration and under the same conditions as the primary polyclonal rabbit antichicken abs against IL-1 $\beta$ and IL-6. This isotype gave a low percentage of positive cells indicating the absence of non-specific binding, as shown in the dot-plots of LPS treated cells below.

Isotype
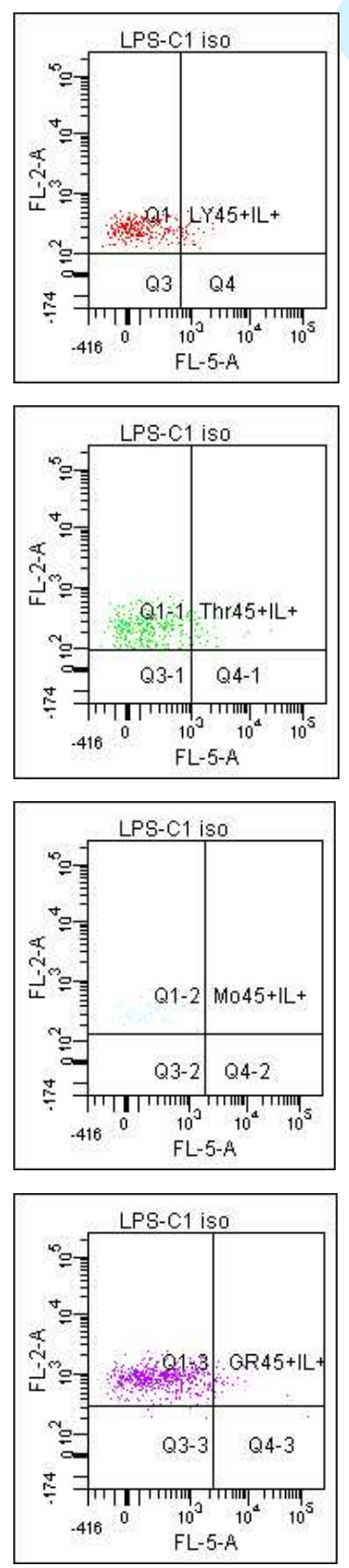

IL-6
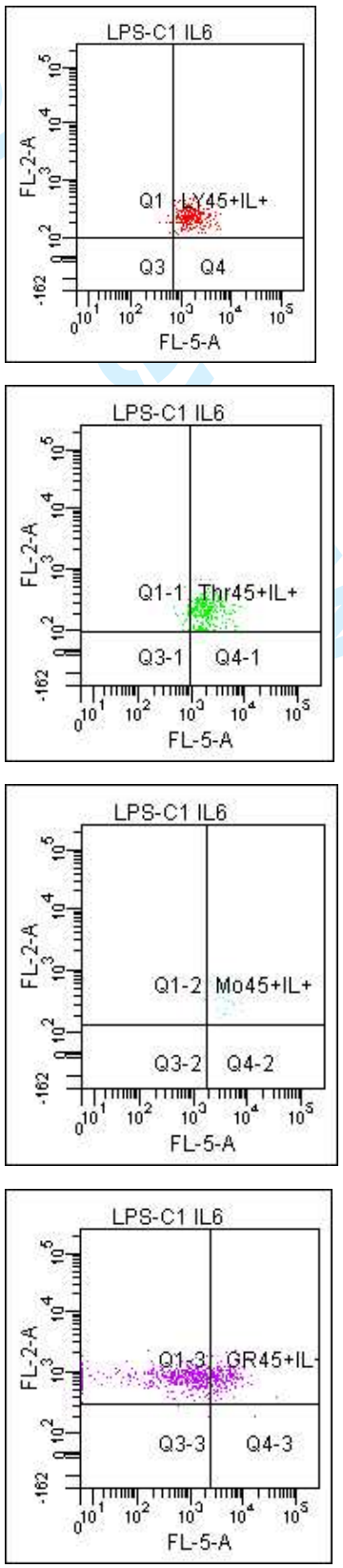
○ Staining of the LPS-treated cells without permeabilising solution was performed, but since the FACSlyse (Becton Dickinson, BD) solution used to lyse the red blood cells has already a significant permeabilization effect, these data could not be used as additional negative control. Indeed, the permeabilization step after incubation with the anti-CD45 antibodies is recommended by BD only to be sure that all cells are properly permeabilized. Therefore, an alternative control for the binding of our abs to the cell surface was carried out by confocal microscopy after stimulation of whole blood with LPS. Cell nuclei were stained using propidium iodide (PI), an Alexa 488-labeled secondary ab was used for visualizing IL-1 $\beta /-6$. Leukocyte differentiation was based on the nuclear morphology and cell size. A representative image (2B) is now included in the revised manuscript illustrating the intracellular staining of chicken lymphocytes for IL-6.

Although the results from both complementary negative control experiments are satisfactory, we propose to include only the confocal image showing the absence of cell surface binding of the abs in the revised manuscript. The reason not to include the isotype control results is that we are not convinced of the added value of this type of control to prove the absence of non-specific binding for our application. Following arguments motivate our decision: the provider of the primary antibodies (Serotec) provided negative advice on the use of a polyclonal isotype ab, while the use of a monoclonal isotype is also not relevant; in general, the use of isotype controls remains to date highly controversial in the field of flow cytometry and recommended typically to test for non-specific binding of monoclonal abs in specific cell types (O'Gorman and Thomas, 1999; Hulspas et al., 2009). To test our argumentation, we evaluated a second polyclonal isotype ab from the same class of immunoglobulin (i.e. IgG) and at the same concentration but with only minor variations in characteristics compared to the first isotype in manufacturing process and formulation (data not shown). This second isotype yielded much much less satisfactory results. 
We are aware that the high concentrations at which our primary abs were used increase the risk for non-specific binding, but we obtained these after appropriate titration of the abs. Addionally, preliminary results using chicken serum in an additional blocking step before labeling with our abs did not have any influence as shown below.
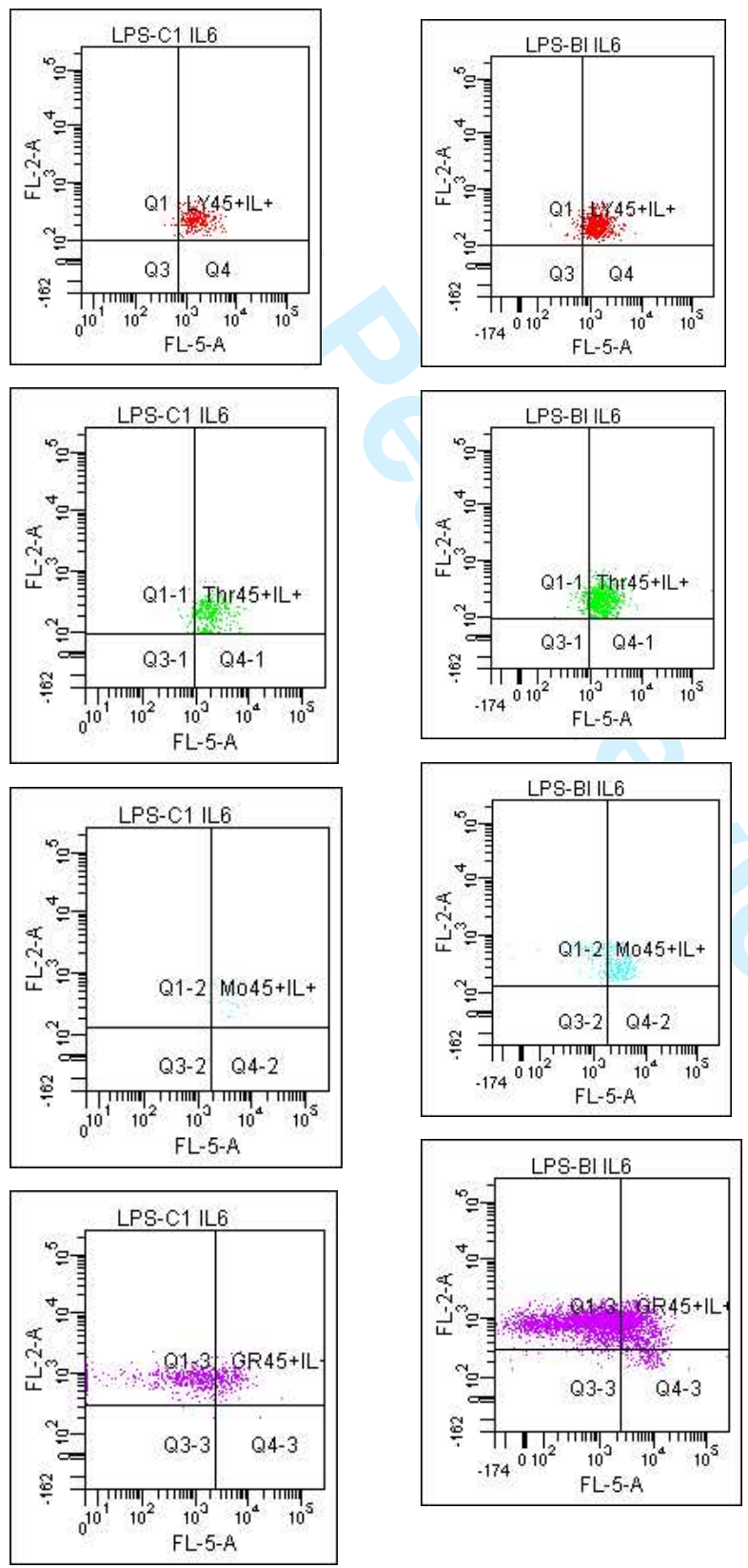

IL-6

with blocking 
Also, autofluorescence and secondary ab controls were systematically used throughout the study. Finally, our in vivo study (De Boever et al., Avian Pathology, in press) shows a consistent increase for both cytokines in LPS- versus sham-inoculated animals in MFI but not in $\%+$ cells of heterophils which are typical candidates for non-specific binding after stimulation.

\section{$\underline{\text { Reviewer } 3}$}

We would like to thank the reviewer for his/her constructive remarks and suggestions which helped us to improve this methodological manuscript.

- The polyclonal antibodies for cytokine detection were purchased at Serotec and their reference numbers have been included in the revised manuscript.

- We agree that the correlation with real-time RT-PCR data is an added value and performed mRNA expression analysis on the same time points as the flow cytometric method in an in vivo study carried out after the current in vitro work (De Boever et al., Avian Pathology, in press). In this latter paper, mRNA levels of IL-1 $\beta$, IL-6 and TL1A (the chicken homologue of mammalian TNF-alpha) were slightly elevated $1 \mathrm{~h}$ after LPS administration. However, care should be taken when comparing the results obtained with both complementary techniques. Because mRNA is extracted from all white blood cells and not from the separate cell types, correlation between mRNA and protein levels is not straightforward.

1. Page 3, line 19: "in mammalia" was changed to "in mammals"

2. Page 3, line 15: a tris-aminomethane/ammoniumchloride buffer was also tested and this is now mentioned in the revised manuscript

3. Page 9, line 15: incubation with $500 \mu 1$ of the permeabilization agent resulted in the highest MFI and \% cytokine+ cells and was therefore used in all subsequent experiments. 


\section{FLOW CYTOMETRIC DIFFERENTIATION OF AVIAN LEUKOCYTES AND} ANALYSIS OF THEIR INTRACELLULAR CYTOKINE EXPRESSION

S. De Boever ${ }^{1}$, S. Croubels ${ }^{1}$, K. Demeyere ${ }^{1}$, B. Lambrecht ${ }^{2}$, P. De Backer ${ }^{1}$, E. Meyer ${ }^{1}$

${ }^{1}$ Department of Pharmacology, Toxicology and Biochemistry, Faculty of Veterinary Medicine, Ghent University, Salisburylaan 133, 9820 Merelbeke, Belgium

${ }^{2}$ Department of Internal Medicine, Faculty of Medicine and Health Science, Ghent University, De Pintelaan 185, 9000 Ghent, Belgium

Running head: Flow cytometric analysis of avian leukocytes

*Author to whom correspondence should be addressed sandra.deboever@ugent.be

Tel.: 0032-9-264.73.24

Fax.: 0032-9-264.74.97 


\begin{abstract}
A flow cytometric method for the identification of chicken blood leukocyte subpopulations and thrombocytes was developed. An anti-chicken CD45 phycoerythrin-labelled antibody was used to separate leukocytes from red blood cell nuclei. Leukocytes and thrombocytes were identified using a combination of their CD45-positivity and their typical side scatter properties. The identity of the CD45-positive cells was confirmed by sorting the subpopulations and subsequent light microscopic evaluation.

In these differentiated cell populations, intracellular expression analysis of the proinflammatory cytokines interleukin-1 $\beta$ and IL-6 was subsequently optimised on whole blood after in vitro stimulation with lipopolysaccharide from Escherichia coli strain O127:B8.
\end{abstract}

Keywords: chicken, leukocyte identification, CD45, cytokine expression 


\section{INTRODUCTION}

Flow cytometry is a preferred method to phenotype ex vivo derived individual leukocytes from various species (Bohls et al., 2006). The flow cytometric differentiation of avian leukocytes has been described for monocytes (Mast et al., 1998), lymphocyte subpopulations (Fair et al., 2008) and thrombocytes (Viertlboeck and Göbel, 2007). Uchiyama et al. (2005) used an aspecific fluorescent lipophilic dye $\mathrm{DiOC}_{6}(3)$ for differentiation and counting of quail and chicken blood cells.

In mammals, the common leukocyte antigen CD45 is a haemopoietic cell-specific surface glycoprotein with a cytoplasmic tyrosine phosphatase domain that is believed to play a role in T- and B cell antigen receptor signal transduction (Tchilian and Beverly, 2006). Various isoforms are expressed on different types of lymphohematopoietic cells, while it is absent on mammalian platelets and mature erythrocytes. The avian CD45 homolog is expressed on all chicken leukocytes but not on erythroid cells (Paramithiotis et al., 1991). Chicken thrombocytes, which are the equivalent of mammalian platelets, also express the CD45 antigen although at consistently lower levels in comparison to lymphocytes (Horiuchi et al., 2004; Viertlboeck and Göbel, 2007).

Avian heterophils, which are the equivalent of mammalian neutrophils, blood monocytes, and thrombocytes, release a cascade of cytokines upon stimulation with various infectious or noninfectious agents such as lipopolysaccharide (LPS) (Rhind et al., 2001; Kogut et al., 2005; Scott et al., 2008; Ferdous et al., 2008). LPS is commonly used to induce an acute phase reaction in humans and animals because of its proinflammatory properties (Skarnes et al., 1981; Klosterhalfen et al., 1992; Erroi et al., 1993; Franco et al., 2000; Maxwell et al., 2002; De Boever et al., 2008). LPS interacts with the innate immune system through Toll-like receptor 4 (TLR4), a member of the family of cell-surface and endosomally expressed receptors that recognize conserved molecular patterns unique to microorganisms (Palsson- 
Mcdermott and O’Neill, 2004; Janssens and Beyaert, 2003). Recognition of microbial components by TLRs triggers a cascade of cellular signals that culminates in the activation of Nuclear Factor $-\kappa \mathrm{B}$ which leads to inflammatory gene expression (Verstrepen et al., 2008). Acute endotoxemia represents an adequate tool for gaining insight in inflammatory processes (Remick and Ward, 2005). Furthermore, such a controlled inflammation model is of interest to test the pharmacodynamic properties of anti-inflammatory drugs. To be able to monitor the progress of the inflammatory response and evaluate the immune-modulatory effect of antiinflammatory drugs, several parameters can be determined including body temperature, blood pressure, cytokine expression and the production of acute phase proteins. Of relevance in this context is that the cytokines IL-1 $\beta$ and IL-6 have been characterized as major endogenous pyrogens or fever-inducers using several animal models (Kluger, 1991; Jakab and Kalabay, 1998; Leon et al., 1999). Flow cytometry is a powerful analytical technique allowing the quantitative assessment of cytokine production at the single cell level. Using multiple colourlabelling, the simultaneous identification of different selected parameters can be performed (Bueno et al., 2001; Schultz et al., 2002; Schuerwegh et al., 2003).

In this paper we describe a flow cytometric method for the identification of avian leukocyte subpopulations and thrombocytes based on their combined CD45 positivity and side scatter properties. The major advantage of this technique is the use of a single antibody directed against a common leukocyte antigen for the identification of the leukocyte subpopulations and thrombocytes. Furthermore, intracellular detection of IL-1 $\beta$ and IL- 6 was performed in these different leukocyte subpopulations. This new tool allows us to monitor the cytokine expression after in vivo LPS administration in broiler chickens. 


\section{MATERIALS AND METHODS}

Blood samples Blood samples $(0.5 \mathrm{ml})$ were collected from the leg vein from laying hens, kept as blood donors, into heparin containing tubes (Venoject ${ }^{\circledR}$, Terumo Corp., Tokyo, Japan). This procedure was approved by the Ethics committee of the Faculty of Veterinary Medicine (EC 2006/035).

Reagents and antibodies The phycoerythrin (PE) conjugated Cell Lab mouse monoclonal anti-chicken CD45 antibody, isotype IgM $\kappa$ was purchased at Analis (Gent, Belgium).

Two polyclonal IgG antibodies, both raised in rabbits and directed against chicken IL-1 $\beta$

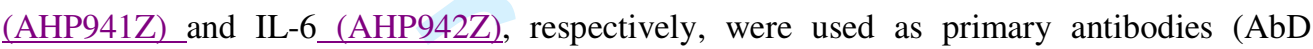
Serotec, Cergy Saint-Christophe, France). An allophycocyanin (APC)-conjugated fragment $\mathrm{F}(\mathrm{ab})_{2}$ of a goat antibody to rabbit immunoglobulin (Santa Cruz biotechnology Inc., Heidelberg, Germany) was used as secondary antibody.

Goat serum, RPMI 1640 and bovine serum albumin (BSA) were purchased at Invitrogen (Merelbeke, Belgium). BD FACS Lysing solution, BD FACS Permeabilizing solution 2 and BD CellFIX were purchased from BD Biosciences (Erembodegem, Belgium).

LPS of Escherichia coli strain O127:B8 was purchased at Sigma-Aldrich (Bornem, Belgium).

Staining procedure and flow cytometric analysis Chicken leukocytes and thrombocytes were obtained from whole blood after lysis of the erythrocytes. For this purpose, $4.5 \mathrm{ml}$ of BD FACS Lysing solution, 1/10 diluted in distilled water, was added to $0.5 \mathrm{ml}$ of blood in a falcon tube for 10 minutes $(\mathrm{min})$ at room temperature. After washing, centrifugation for 5 min at $500 \mathrm{~g}$, the pellet was resuspended in $500 \mu \mathrm{l} \mathrm{RPMI}$ and $50 \mu \mathrm{l}$ was pipetted into a flow cytometer tube. Following titration, testing 4, 6, 8, 10 and $20 \mu \mathrm{g} / \mathrm{ml}$ as concentrations, 
the PE-labelled anti-CD45 was added in a final concentration of $6 \mu \mathrm{g} / \mathrm{ml}$ and samples were incubated for $30 \mathrm{~min}$ at $4^{\circ} \mathrm{C}$.

For the in vitro stimulation with LPS, $0.5 \mathrm{ml}$ of whole blood was incubated with LPS at a final concentration of $10 \mu \mathrm{g} / \mathrm{ml}$ for 3 hours at $37^{\circ} \mathrm{C}$ in a shaking warm water bath (Memmert, Model WNB 14, Schwabad, Germany). Subsequently, erythrocytes were lysed and leukocytes and thrombocytes were labelled as described above, followed by permeabilisation using BD FACS Permeabilizing solution 2, 1/10 diluted with distilled water, again for $10 \mathrm{~min}$ at room temperature. As for CD45, the optimal working dilutions for the primary antibodies directed against IL-1 $\beta$ and IL-6 were also optimized by means of titration, testing 1.6, 3.3, 6.6, 10, $12.5,25,50$ and $100 \mu \mathrm{g} / \mathrm{ml}$ as concentrations. A final concentration of $50 \mu \mathrm{g} / \mathrm{ml}$ was used and samples were incubated for $30 \mathrm{~min}$ at room temperature. Blocking was performed by adding $20 \%$ goat serum in RPMI for $30 \mathrm{~min}$ at room temperature. Finally, the APC-labelled secondary antibody was added at a concentration of $6 \mu \mathrm{g} / \mathrm{ml}$ for $30 \mathrm{~min}$ at $4^{\circ} \mathrm{C}$. Cells were resuspended in $450 \mu \mathrm{l}$ CellFIX, $1 / 10$ diluted with distilled water. The optimal antibody concentration of the primary and secondary antibody were also determined by titration.

Samples were measured using a double laser bench top flow cytometer FACSCanto (Beckton Dickinson Biosciences) and analysed with FACSDiva Software (Becton Dickinson). Excitation was performed with a $488 \mathrm{~nm}$ argon-ion laser and emission collected using a 530/30 $\mathrm{nm}$ band pass (BP) filter for FITC conjugates, a 585/42 nm BP filter for PE conjugates and a 660/20 nm BP filter for APC conjugates. Two basic parameters, i.e. the side scatter (SSC), which is proportional to the cellular granularity, and the forward scatter (FSC) which is proportional to cell size, were analyzed. For the CD45 expression, the amount of CD45 antigen present per cell (mean fluorescence intensity, MFI) was determined in all populations as can be seen in Figure 3. 
For the cytokine expression, the $\%$ of IL-1 $\beta$ and IL-6 positive cells and their MFI were assessed after differentiation based on CD45 positivity and SSC as described above. Additionally, flow cytometric cell sorting was performed on $\mathrm{CD}_{4} 5^{+}$cells (BD FACSAria II, California, USA). The sorted cell populations were stained (Diff-Quick, Acros Organics N.V., Geel, Belgium) after cytocentrifugation (Shandon, UK) and subsequent analysis of the slides by light microscopy (Olympus BX-UCB, Pennsylvania, USA).

\section{RESULTS AND DISCUSSION}

The aim of this study was two-fold, i.e. to develop (1) a straightforward method to differentiate avian white blood cells and (2) to enable the subsequent assessment of their individual intracellular cytokine expression after LPS challenge.

(1) Flow cytometric identification of avian monocytes (Mast et al., 1998), lymphocyte subpopulations (Bohls et al., 2006; Fair et al., 2008) and thrombocytes (Viertlboeck and Göbel, 2007) has already been performed. The aspecific fluorescent lipophilic dye $\mathrm{DiOC}_{6}(3)$ used by Uchiyama et al. (2005) for differentiation, was very useful for counting of quail and chicken blood cells. We succeeded in the development of a straightforward method to differentiate leukocyte subpopulations and thrombocytes using a single antibody directed against the common leukocyte antigen. The CD45 antibody used in the current study allows a better discrimination between the leukocyte subpopulations. This is especially the case for the lymphocytes and thrombocytes because of the reduced interference with the red blood cell nuclei. The presence of nucleated erythrocytes and thrombocytes was indeed a challenge as this is a major difference between mammalian and avian hematology (Campbell and Ellis, 2007). Lysis of the erythrocytes was tested comparing a Tris-aminomethane/ $\mathrm{NH}_{4} \mathrm{Cl}$ buffer with the commercial lysing solution, with the latter giving the best results (data not shown). Nevertheless, after lysis, the red blood cell nuclei were still present and since their size is 
similar to that of a small lymphocyte, the discrimination between both events was not possible based on the commonly used FSC versus SSC dot-plot as illustrated in Figure 1 (A). However, the combined use of an anti-chicken CD45 antibody and the SSC, enabled the discrimination between lymphocytes and red blood cell nuclei. On the representative dot plot showing $\mathrm{CD}^{+} 5^{+}$cells versus SSC, the different subpopulations, i.e. lymphocytes, thrombocytes, monocytes and heterophils, could be gated (Figure $1 \mathrm{~B}$ ). The position of the different subpopulations on the dot plot is similar to mammalian species, except for the thrombocytes, which are not present in mammalian blood (Figure $1 \mathrm{C}$ ).

The optimal concentration of the anti-CD45 antibody $(6 \mu \mathrm{g} / \mathrm{ml})$ was determined by titration (data not shown).

To confirm the identity of the gated populations on the anti CD45-PE versus SSC dot-plot, additional sorting was performed, followed by light microscopy (Figure 2). Population L was composed of lymphocytes, characterized by a round nucleus and weakly basophilic cytoplasm. Population M, contains the monocytes with the hallmarks being the largest leukocytes and having a large nucleus. The heterophils (population $\mathrm{H}$ ) are characterized by a lobed nucleus and abundant eosinophilic granules in the cytoplasm. For the heterophils and lymphocytes, a purity of $96 \%$ and $89.4 \%$ could be calculated, respectively. For the monocytes and thrombocytes no percentages can be provided as only few cells were present on the slide. (2) In a second series of experiments the optimized cell differentiation method was combined with intracellular detection of pro-inflammatory cytokines. More specifically, IL-1 $\beta$ and IL-6 were chosen since these cytokines have been implicated as key mediators of fever (Kluger, 1991; Jakab and Kalabay, 1998; Leon et al., 1999). Commercial antibodies directed against chicken IL-1 $\beta$ and IL-6 are of polyclonal origin and have not yet been tested for flow cytometry. In the current experiment, the method was optimized after in vitro stimulation of heparin-treated whole blood samples with LPS, because cell activation has been reported to 
be better and cytokine expression is more efficient than with other anticoagulants (Coló Brunialti et al., 2002). Both a commercial lysing agent, BD FACS Lysing solution and a trisaminomethane/ $\mathrm{NH}_{4} \mathrm{Cl}$ buffer were tested, with the former giving the best results. It should be remarked that we deliberately chose not to use a secretion block in the in vitro experiments, to mimic the in vivo situation as closely as possible. Moreover, the use of a fixation-containing lysing agent in the first step of the protocol, prevents cytokine secretion after sampling. Several amounts of the commercial permeabilizing solution were tested, with $500 \mu$ l resulting in the highest percentage of cytokine expressing cells and the highest MFI (data not shown). As for CD45, the optimal working dilutions for the primary antibodies directed against IL-1 $\beta$ and IL-6 were also optimized by means of titration (data not shown). An APC-labeled secondary antibody was chosen for intracellular cytokine detection. APC belongs to a family of phycobiliproteins with a broad excitation spectrum and a large Stoke's shift with a high quantum yield fluorescence (Jung and Dailey, 1989; Telford et al., 2001). The optimal concentration of the secondary antibody was also determined by titration.

A fluorescein isothiocyanate (FITC) labelled antibody was first tested as secondary antibody, but since preliminary data confirmed that FITC stains the cytoplasmic granules of avian heterophils (Rath et al., 1998), this fluorochrome was not suited for intracellular cytokine detection nor could FITC-labelled antibodies be used for the identification of the different leukocyte subpopulations.

After stimulation of whole blood with LPS, cytokine production was measured in the leukocyte subpopulations and the thrombocytes as illustrated in Figure 3. The MFI of LPS stimulated cells for both cytokines is shown in Table 1 . On the dot plot of samples to which only the CD45-PE antibody and the secondary APC-labelled antibody was added (Figure 3 A), a grid was placed to be able to discriminate between specific and nonspecific staining of the secondary antibody. As could be expected from literature (Schultz et al., 2002; 
Schuerwegh et al., 2003), stimulation with LPS evoked a right-shift of the populations, indicating the intracellular presence of IL-1 $\beta$ and IL-6. Monocytes showed the largest shift, both for IL-1 $\beta$ and IL-6. Thrombocytes are also capable of synthesizing cytokines. This observation is in accordance with Scott et al. (2007) and Ferdous et al. (2008), although in those experiments IL-1 $\beta$ and IL-6 expression was measured on the mRNA level. The heterophils expressed the lowest level of cytokines, although mRNA expression after LPS stimulation is reported (Kogut et al., 2005). However, the latter authors mention that mRNA levels do not necessarily equate to bioactive protein. A confocal microscopic image of a lymphocyte expressing IL-6 is shown in Figure 2B.

Finally, it should be remarked that the heterophils clearly expressed more CD45 molecules after LPS stimulation (data not shown). This observation corroborates findings in human granulocytes that contain an intracellular pool of CD45 and upon stimulation with formylmethionylleucylphenylalanine, ionophore A23187 or LPS increase the surface expression of CD45 (Lacal et al., 1988; Caldwell et al., 1991; Stie and Jesaitis, 2007).

In conclusion, we developed a straightforward method for the differentiation of the different leukocyte subpopulations in avian blood, using a monoclonal antibody directed against chicken CD45 in combination with SSC properties. Furthermore, intracellular IL-1 $\beta$ and IL-6 expression in these individual populations was assessed. This method can now be applied for the detection of intracellular cytokine expression after intravenous administration of LPS to broiler chickens.

\section{ACKNOWLEDGEMENTS}

The authors would like to thank E. Neirinckx, D. De Clercq and K. Jonckheere for the help with the animal experiment. 


\section{REFERENCES}

Bohls, R.L., Smith, R., Ferro, P.J., Silvy N.J., Li, Z., Collison E.W. (2006). The use of flow cytometry to discriminate avian lymphocytes from contaminating thrombocytes. Developmental and Comparative Immunology, 30, 843-850.

Bueno, C., Almeida, J., Alguero M.C., Sànchez, M.L., Vaquero, J.M., Laso, F.J., San Miguel, J.F., Escribano, L., Orfao, A. (2001). Flow cytometric analysis of cytokine production by normal human peripheral blood dendritic cells and monocytes: comparative analysis of different stimuli, secretion-blocking agents and incubation periods. Cytometry, 46, 33-40.

Caldwell, C.W., Patterson, W.P., Yesus, Y.W. (1991). Translocation of CD45RA in neutrophils. Journal of Leukocyte Biology, 49, 317-328.

Campbell, T.W., Ellis, C.K. (2007). Avian \& exotic animal hematology \& cytology, Third edn (320 pp). Carlton: Blackwell Publishing.

Coló Brunialti, M.K., Kallás, E.G., Freudenberg, M., Galanos, C., Salomao, R. (2002). Influence of EDTA and heparin on lipopolysaccharide binding and cell activation, evaluated at single-cell level in whole blood. Cytometry, 50, 14-18.

De Boever, S., Beyaert, R., Vandemaele, F., Baert, K., Duchateau, L., Goddeeris, B., De Backer, P., Croubels, S. (2008). The influence of age and repeated lipopolysaccharide administration on body temperature and the concentration of interleukin- 6 and IgM antibodies in broiler chickens. Avian Pathology, 37, 39-44.

Erroi, A., Fantuzzi, G., Mengozzi, M., Sironi, M., Orencole, S.F., Clark, B.D., Dinarello, C.A., Isetta, A., Gnocchi, P., Giovarelli, M., Ghezzi, P. (1993). Differential regulation of cytokine production in lipopolysaccharide tolerance in mice. Infection and Immunology, 61, 4356-4359. 
Fair, J.M., Taylor-McCabe, K.J., Shou, Y., Marrone, B.L. (2008). Immunophenotyping of chicken peripheral blood lymphocyte subpopulations: Individual variability and repeatability. Veterinary Immunology and Immunopathology, 125, 286-273.

Ferdous, F., Maurice, D., Scott, T. (2008). Broiler chick thrombocyte response to lipopolysaccharide. Poultry Science, 87, 61-63.

Franco, R.F., de Jonge, E., Dekkers, P.E.P., Timmerman, J.J., Spek, C.A., van Deventer, S.J.H., van Deursen, P., van Kerkhoff, L., van Gemen, B., ten Cate, H., van der Poll, T., Reitsma, P.H. (2000). The in vivo kinetics of tissue factor messenger RNA expression during human endotoxemia: relationship with activation of coagulation. Blood, 96, 554-559.

Horiuchi, H., Tanaka, K., Shigata, A., Yoshida, K., Kushima, K., Ohta, H., Furusawa, S., Matsuda, H. (2004). A monoclonal antibody against chicken thrombocytes reacts with the cells of thrombocyte lineage. Immunolology, 66, 243-250.

Janssens, S. \& Beyaert, R. (2003). Role of Toll-like receptor in pathogen recognition. Clinical Microbiology Reviews, 16, 637-646.

Jakab, L., Kalabay, L. (1998). The acute phase reaction syndrome: the acute phase reactants. Acta Microbiologica et Immunologica Hungarica, 45, 409-418.

Jung, T.M., Dailey, M.O. (1989). A novel and inexpensive source of allophycocyanin for multicolour flow cytometry. Journal of Immunological Methods, 121, 9-18.

Klosterhalfen, B., Hörstmann-Jungemann, K., Vogel, P., Flohé, S., Offner, F., Kirkpatrick, C.J., Heinrich, P.C. (1992). Time course of various inflammatory mediators during recurrent endotoxemia. Biochemical Pharmacology, 43, 2103-2109.

Kluger, M. (1991). Fever: role of pyrogens and cryogens. Physiological Reviews, 14, 93-127.

Kogut, M.H., Iqbal, M., He, H., Philbin, V., Kaiser, P., Smith, A. (2005). Expression and function of Toll-like receptors in chicken heterophils. Developmental and Comparative Immunology, 29, 791-807. 
Lacal, P., Pulidos, R., Sànchez-Madrid, F., Mollinedo, F. (1988). Intracellular location of T200 and Mol glycoproteins in human neutrophils. Journal of Biological Chemistry, 20, 9946-9951.

Leon, L.R., Kozak, W., Rudolph, K., Kluger, M.J. (1999). An antipyretic role for interleukin 10 in LPS fever in mice. American Journal of Physiology, 276, R81-89.

Mast, J., Goddeeris, B., Peeters, K., Vandesande, F., Berghman, L. (1998). Characterization of chicken monocytes, macrophages and interdigitating cells by the monoclonal antibody KUL01. Veterinary Immunology and Immunopathology, 61, 343-357.

Maxwell, J.R., Ruby, C., Kerkvliet, N.I., Vella, A.T. (2002). Contrasting the role of costimulation and the natural adjuvant lipopolysaccharide during the induction of $\mathrm{T}$ cell immunity. Journal of Immunology, 168, 4372-4381.

Pålsson-McDermott, E. \& O’Neill, L. (2004). Signal transduction by the lipopolysaccharide receptor, Toll-like receptor-4. Immunology, 113, 153-162.

Paramithiotis, E., Tkalec, L., Ratcliffe, J.H. (1991). High levels of CD45 are co-ordinately expressed with CD4 and CD8 on avian thymocytes. Journal of Immunology, 11, 3710-3717. Rath, N.C., Huff, G.R., Balog, J.M., Huff, W.E. (1998). Fluorescein isothiocyanate staining and characterization of avian heterophils. Veterinary Immunology and Immunopathology, 64, 83-95.

Remick, D.G., Ward, P.A. (2005). Evaluation of endotoxin models for the study of sepsis. Shock, 24, 7-11.

Rhind, S.G., Castellani, J.W., Brenner, I.K.M., Shephard, R.J., Zamecnik, J., Montain, S.J., Young, A.J., Shek, P.N. (2001). Intracellular monocyte and serum cytokine expression is modulated by exhausting exercise and cold exposure. American Journal of Physiology Regulatory, Integrative and Comparative Physiology, 281, R66-R75. 
Schuerwegh, A., De Clerck, L., Bridts, C., Stevens, W. (2003). Comparison of intracellular cytokine production with extracellular cytokine levels using two flow cytometric techniques. Cytometry Part B, 55B, 52-58.

Schultz, C., Rott, C., Temming, P., von Puttkammer, J., Bucsky, P. (2002). Influence of specimen age and use of different negative controls in determination of intracytoplasmic levels of cytokines after whole-blood culture assay. Clinical Diagnostic Laboratory Immunology, 9, 295-298.

Scott, T., Owens, M.D. (2008). Thrombocytes respond to lipopolysaccharide through Toll-

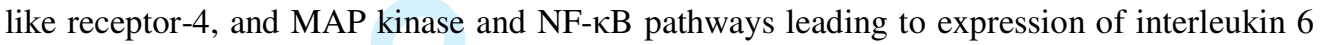
and cyclooxygenase-2 with production of prostaglandin E2. Molecular Immunology, 45, 1001-1008.

Skarnes, R.C., Brown, S.K., Hull, S.S., McCracken, J.A. (1981). Role of prostaglandin E in the biphasic fever response to endotoxin. Journal of Experimental Medecine, 154, 1212-1224. Stie, J., Jesaitis, A.J. (2007). Reorganization of the human neutrophil plasma membrane is associated with functional priming: implications for neutrophil preparations. Journal of Leukocyte Biology, 81, 672-685.

Tchilian, E.Z., Beverly, P.C.L. (2006). Altered CD45 expression and disease. TRENDS in Immunology, 27, 146-153.

Telford, W.G., Moss, M.W., Morseman, J.P., Allnutt, F.C. (2001). Cryptomonad algal phycobiliproteins as fluorochromes for extracellular and intracellular antigen detection by flow cytometry. Cytometry, 44, 16-23.

Uchiyama, R., Morimoto, T., Kai, O., Uwatoko, K., Inoue, Y., Nakanishi, T. (2005). Counting absolute number of lymphocytes in quail whole blood by flow cytometry. Avian Pathology, 67, 441-444. 
Verstrepen, L., Bekaert, T., Chau, T., Tavernier, J., Chariot, A. \& Beyaert, R. (2008). TLR-4, IL-1R, TNF-R signalling to NF-kappaB: variations on a common theme. Cellular and Molecular Life Science, 65, 2965-2978.

Viertlboeck, B.C., Göbel, T.W. (2007). Chicken thrombocytes express the CD51/CD61 integrin. Veterinary Immunology and Immunopathology, 119, 137-141. 


\section{Figure captions:}

Figure 1: (A) Representative flow cytometrical SSC versus FSC dot plot of chicken blood after red blood cell lysis, without CD45 labelling, (B) representative flow cytometrical anti CD45-PE versus SSC dot-plot of a chicken blood sample after lysis of the erythrocytes (L: lymphocytes, TH: thrombocytes, M: monocytes and H: Heterophils), (C) representative flow cytometrical SSC versus FSC dot-plot showing the populations gated on dot-plot B

Figure 2 (A): Microscopic image of sorted lymphocytes (L), monocytes (M) and heterophils (H) after Diff-Quick staining, (B) a confocal microscopic image of a lymphocyte expressing IL-6 (white arrow) surrounded by red blood cell nuclei. The secondary antibody was labeled with Alexa 488 and propidium iodide was used to stain the nucleus.

Figure 3: Representative flow cytometrical dot-plots of in vitro stimulated heterophil (H), monocyte (M), thrombocyte (TH) and lymphocyte (L) populations (A) after addition of anti$\underline{\text { CD45 PE and of the secondary APC-labelled antibody without the primary IL antibodies; (B) }}$ addition of anti-CD45 PE, the primary antibody directed against IL-1 $\beta$ and the secondary APC-labelled antibody; (C) addition of anti-CD45 PE labelled antibody, the primary antibody directed against IL-6 and the secondary APC-labelled antibody. Autofluorescence was consistently lower than $10^{2}$ for all samples. The mean $\%$ of positive events \pm standard error of the mean $(n=6)$ is mentioned in the upper right quandrants. 